\title{
Thoracoscopic treatment of iatrogenic injuries of the tracheobronchial tree: a retrospective analysis of 5 cases and review of the literature
}

\author{
Aliaksandr Karpitski ${ }^{1}$, Andrej Shestiuk ${ }^{2}$, Siarhei Panko ${ }^{3}$, Henadzi Zhurbenka ${ }^{1}$, Denis Vakulich ${ }^{1}$, Aliaksandr Ihnatsiuk ${ }^{1}$ \\ ${ }^{1}$ Department of Thoracic Surgery, Brest Regional Hospital, Brest, Belarus \\ ${ }^{2}$ Department of Anatomy and Physiology, Brest State University, Brest, Belarus \\ ${ }^{3}$ Collegium Medicum, Jan Kochanowski University, Kielce, Poland
}

Videosurgery Miniinv 2022; 17 (1): 240-244

DOI: https://doi.org/10.5114/wiitm.2021.107816

\begin{abstract}
Introduction: latrogenic injuries to the trachea and main bronchi present one of the most dramatic complications traditionally treated by thoracotomy and transcervical-transtracheal approaches but almost never by video-assisted thoracic surgery.

Aim: To evaluate our experience in a video-assisted thoracic surgery repair of iatrogenic tracheal lacerations.

Material and methods: The group under analysis consisted of 5 consecutive patients (1 male, mean age: 52 years, range: 32-56 years) who were treated for postintubation and intraoperative damage to the tracheobronchial tree using video-assisted thoracic surgery within the period 2015-2018. Thoracic computed tomography and fibreoptic tracheobronchoscopy were used to confirm iatrogenic tracheal ruptures before surgery. The membranous rupture of the trachea was closed with interrupted absorbable sutures, which were additionally sutured through the oesophageal wall or the wall of the gastric conduit to strengthen the suture line. Postoperative treatment included broad-spectrum antibiotic therapy and control tracheobronchoscopy.

Results: The average duration of thoracoscopic tracheal rupture repair with suture line reinforcement was 103 min (range: 60-180 min). All patients were treated thoracoscopically without resorting to open surgery and were discharged without any postoperative complications within 16 days (range: 8-22 days).

Conclusions: The minimally invasive thoracoscopic approach may be the method of choice for the treatment of intraoperative and post-intubation injuries of the tracheobronchial tree.
\end{abstract}

Key words: iatrogenic injury, tracheobronchial tree, video-assisted thoracoscopic surgery.

\section{Introduction}

latrogenic injuries of the tracheobronchial tree are rare but dramatic and potentially lethal complications of some procedures such as orotracheal intubation, percutaneous dilational tracheostomies, mediastinoscopy, and excision of advanced tumours with mediastinal involvement [1-3]. The membranous tracheobronchial damage can sometimes be caused by compression of the trachea with oesophageal prostheses [4] and intratracheal stent insertion [5]. Therapeutic options (conservative or surgical) for iatrogenic tracheobronchial ruptures (ITR) are still under debate. However, surgical repair is used in more than 50\% [6] of the cases even though conservative therapy development allows successful conservative management of some lesions up to $7.5 \mathrm{~cm}$

\section{Address for correspondence}

Prof. Siarhei Panko, Collegium Medicum, Jan Kochanowski University, Kielce, Poland, phone: +37 5291108819 ,

e-mail: sppankam@gmail.com 
in size [7]. Surgical treatment is indicated in ITR patients with the following: (1) intra-operatively diagnosed injuries [8], (2) postintubation para-carinal lacerations, (3) progressive pneumomediastinum, subcutaneous emphysema and a mediastinitis, (4) major air leak via pleural drainages, and (5) large defect size (>3-4 cm or > 1/3 diameter, especially with prolapsed oesophageal wall) [9].

Primary repair is the treatment of choice in ITR, but the surgical approach depends on the laceration site [10]. If the injury occurs in the proximal $2 / 3$ of the trachea, the preferred incision site may be the neck [11], while injures to the distal trachea with bifurcation and both main bronchi [12] require a thoracotomy. Many different effective techniques involving reinforcement and/or buttressing of the suture line have been described for the mentioned approaches, but only a few of them employed video-assisted thoracic surgery (VATS).

\section{Aim}

The purpose of our research was to analyse our experience of ITR treatment using minimally invasive thoracoscopic procedures.

\section{Material and methods}

We performed a retrospective review of the data received from 5 consecutive patients (1 male) with a mean age of 52 years (range: $32-56$ years) treated for iatrogenic injuries to the tracheobronchial tree (ITR) by video-assisted thoracic surgery repair (VATS-R) at our hospital between October 2015 and April 2018.

The study was approved by our institutional ethics committee. Written informed consent from the patients was waived because this was a retrospective study, and this consent had been obtained from each patient before any surgery/invasive procedures were performed. The demographic and clinical characteristics of the patients prior to the onset of the VATS-R treatment are summarized in Table I.

The urgent examination techniques employed before the surgery were thoracic computed tomography (TCT) and fibreoptic tracheobronchoscopy (FBS).

Surgical technique for VATS repair of the tracheal laceration.

The patient was intubated with a single lumen tube positioned in the left main bronchus and turned to the left lateral decubitus position.

The surgery was performed by a team of 2 thoracic surgeons.

Four trocars were placed into the right pleural cavity to perform VATS oesophagectomy and/or repair all these lacerations: a 12-millimetre optical port was inserted in the $7^{\text {th }}$ intercostal space along the posterior axillary line, a $10-\mathrm{mm}$ port was placed in the $4^{\text {th }}$ intercostal space along the mid-axillary line, one $5-\mathrm{mm}$ port was located at the level of the scapula angle, and the other one was placed in the $4^{\text {th }}$ intercostal space along the posterior axillary line. After the mobilization of the trachea, its rupture was closed using interrupted U-type absorbable sutures of the Vicril 2.0, which, having been tied together outside the lumen of the trachea, were additionally sutured through the wall of the oesophagus (P1-3) or the wall of the gastric conduit/tube (P4 and P5) to cover the suture line. When the absence of air leakage through the reinforced repair site was confirmed by an intraoperative underwater pressure test (30 $\mathrm{cm} \mathrm{H} \mathrm{H}_{2} \mathrm{O}$ ), the pleural cavity was drained with

Table I. Clinical features and causes of the membranous tracheal rupture

\begin{tabular}{|c|c|c|c|c|c|c|c|c|}
\hline Patient & $\begin{array}{c}\text { Age } \\
\text { [years]/ } \\
\text { sex }\end{array}$ & Height $[\mathrm{cm}]$ & BMI $\left[\mathrm{kg} / \mathrm{m}^{2}\right]$ & Aetiology & $\begin{array}{c}\text { Signs- } \\
\text { symptoms }\end{array}$ & $\begin{array}{c}\text { Delay in the } \\
\text { diagnosis } \\
\text { [h] }\end{array}$ & Location & $\begin{array}{c}\text { Length } \\
{[\mathrm{mm}]}\end{array}$ \\
\hline 1 & $65 / F$ & 156 & 37 & EIOTI & PSM-Emph & 5 & Lower $1 / 3$ & 50 \\
\hline 2 & $32 / M$ & 175 & 27 & EmOTI & $\begin{array}{l}\text { PSM-Emph, } \\
\text { BiPn }\end{array}$ & 6 & $\begin{array}{c}\text { Lower } 1 / 3 \\
\text { + carina }\end{array}$ & 60 \\
\hline 3 & $56 / F$ & 165 & 26 & EmOTI & $\begin{array}{c}\text { PSM-Emph, } \\
\text { UnPn }\end{array}$ & 96 & Lower $1 / 3$ & 50 \\
\hline 4 & $57 / F$ & 170 & 17 & VATS-ES & IOVis & 0 & Middle $1 / 3$ & 30 \\
\hline 5 & $52 / F$ & 173 & 26 & VATS-ES & PerAir & 24 & Lower $1 / 3$ & 35 \\
\hline
\end{tabular}

BMI - body mass index, EIOTI - elective orotracheal intubation, EmOTI - emergency orotracheal intubation, VATS-Eso - video-assisted thoracic surgery oesophagectomy, PSME-mph - progressive subcutaneous and mediastinal emphysema, BiPn - bilateral pneumothorax, UnPn - unilateral pneumothorax, IOVis - intraoperative visualization, PerAir - persistent postoperative air leakage via pleural drainage. 
2 chest tubes, 1 of which was placed near the suture line, and then trocar wounds were sutured. At the end of the operation, all of the patients were extubated in the operating room. Postoperative medical treatment included broad-spectrum antibiotic therapy against tracheobronchial flora and anti-inflammatory therapy. All patients underwent a FBS control and were informed, before leaving the hospital, about the initial symptoms of airway obstruction and stenosis, as well as the need to immediately contact our department if these symptoms appeared.

\section{Results}

The cause of these lacerations in 3 patients was a single lumen tube orotracheal intubation for emergency ( 2 patients) and elective (1 patient) surgery outside the chest. All the patients with a postintubation tracheal injury had mild-to-severe obesity (BMI range: $26-39 \mathrm{~kg} / \mathrm{m}^{2}$ ) as a risk factor, and 2 of them were females aged $>50$ years with short stature. In the remaining patients, tracheal damage occurred during a video-assisted thoracoscopic resection of the oesophagus for surgical treatment of the fourth stage of achalasia - the sigmoid oesophagus. In 4 patients, chest TCT and FBS were used to confirm clinical suspicions and to determine the location and the extent of the membranous tracheal wall rupture, and in 1 the tracheal damage was diagnosed intraoperatively by direct visualization (Table I). Mean length of

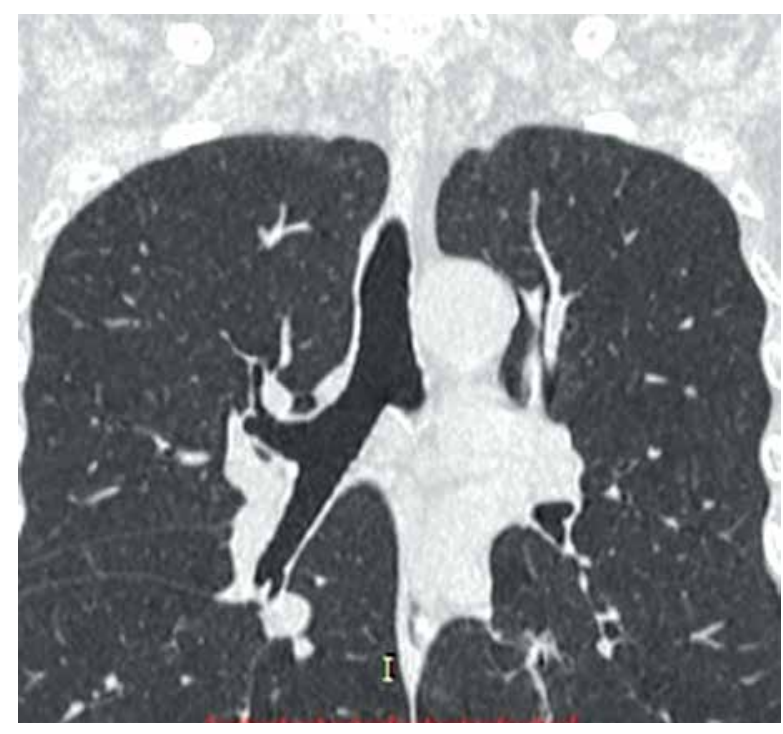

Photo 1. A chest CT scan obtained 23 months after VATS treatment in patient 3 confirmed the absence of tracheal deformities or stenosis injury was $45 \mathrm{~mm}$, ranging from 35 to $60 \mathrm{~mm}$. Two post-intubation cases of ITR were suspected immediately after extubation, confirmed by TCT and FBS, and delivered to our department from other hospitals within 5-6 h. The third post-intubation patient (P3) with no tracheal rupture signs and symptoms was referred to our hospital on the third postoperative day after a laparoscopic emergency cholecystectomy for obstructive jaundice (choledocholithiasis) and cholangitis treatment. Tracheal injury symptoms (Table I) appeared unexpectedly in this patient and were discovered by an anaesthesiologist inducing general gas mixture anaesthesia through a mask to perform endoscopic papillosphincterotomy. The injury to the distal third of the trachea was confirmed by prompt FBS, which revealed a calloused rupture with maceration and fibrin plaques. Having had her right pleural cavity drained and prompt TCT performed, the patient underwent the VATS-R with simultaneous endoscopic papillosphincterotomy and laparoscopic drainage of the ductus choledochus. A month later, when she was re-hospitalized, the choledochal stone was endoscopically extracted with a Dormia basket. Two years later, TCT (Photo 1) and FBS control (Photo 2) showed no signs of tracheal stenosis in this patient. In patients with end-stage achalasia, who underwent thoracoscopic resection of the oesophagus before the creation of a gastric conduit

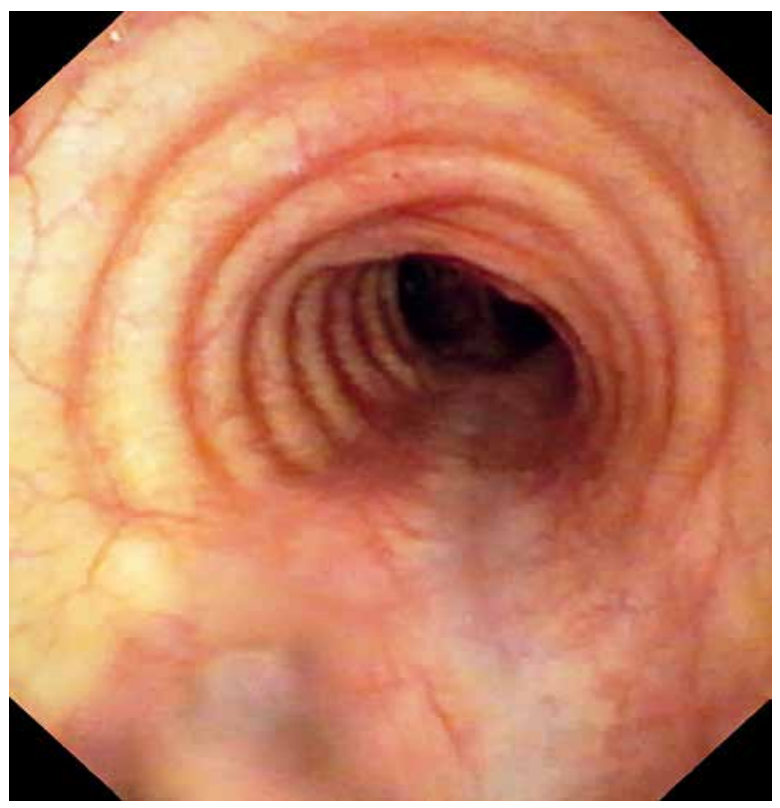

Photo 2. An endoscopic view of a thin epithelialized postoperative scar on the membranous tracheal wall after 23 months in patient 3 
and a gastro-oesophageal anastomosis in the neck by open surgery, the tracheal rupture was diagnosed intraoperatively by direct visualization in one (P4) and by TCT and FBS on the next postoperative day in another patient (P5). Thus, the diagnostic delay between the intervention that caused the injury and its confirmation ranged from 0 (intraoperative finding) to $96 \mathrm{~h}$ (postintubation "hidden damage"), but most injuries were diagnosed within the first $24 \mathrm{~h}$. Therefore, although prompt diagnosis is essential for patients' survival, the mean diagnostic delay was $26 \mathrm{~h}$, which corresponds to other authors [13]. The mean duration of the VATS repair with the suture line reinforcement was $103 \mathrm{~min}$ (ranging from 60 to $180 \mathrm{~min}$ ). The postoperative course was uneventful in all the patients, who were discharged on average after 16 days (ranging from 8 to 22 days) without any respiratory and swallowing problems. An FBS control performed prior to discharge from the hospital revealed per primam healing of these injuries in each case. To date, based on the information obtained from the patients by telephone follow-up surveys, none of them have needed additional consultations and treatment of airway complications.

\section{Discussion}

The incidences of iatrogenic tracheal rupture presented in research literature are as follows: $0.05-0.37 \%$ cases took place during endotracheal intubation [1], 0.4\% - during thoracoscopic and transhiatal resection of the oesophagus, and $0-0.2 \%$ cases during open oesophageal surgery [3]. The ITR incidence is related to objective conditions of instrumentation, associated illnesses in patients and their morphology, the medical staff's experience and skills, etc. [8]. However, the real incidence of the intraoperative and postintubation injury to the tracheobronchial tree is difficult to estimate because these complications have no statistical code of their own in the $10^{\text {th }}$ Revision of the International Statistical Classification of Diseases and Related Health Problems (ICD-10). Research literature contains no data regarding the incidence of injury to the trachea or main bronchi during a VATS esophagectomy, although tracheal injuries may occur in $1-10 \%$ of non-VATS oesophagectomies [14]. A classic surgical approach to tracheobronchial injury repair is right posterolateral thoracotomy through the fourth or fifth intercostal space, which offers excellent expo- sure to the distal trachea with bifurcation and both primitive bronchi [12]. In recent years, there has been a strong trend towards non-operative and minimal invasive management of iatrogenic tracheal injuries [6]; however, thoracoscopic minimally invasive techniques are seldom mentioned in research literature [15]. During its historical evolution, ITR surgical treatment has evolved from open surgical approaches to all cases (preferably by thoracotomy) through varying transcervical-transtracheal approaches [16], using a fibreoptic bronchoscope [17] and other mini-optic instruments as guiding tools [18] to full minimally invasive techniques based on VATS [15]. However, for no clear reason, the use of the latter in the treatment of intraoperative [3] and postintubation [15] injuries has received little coverage in research literature. We were unable to find any descriptions of intraoperative injury to the trachea in the course of subtotal VATS oesophagectomy for the treatment of achalasia (P4), or the same aetiology injury with a postoperative 24-hour diagnostic delay (P5), which were treated by full minimally invasive VATS repair, when the rupture of the trachea may have occurred due to the damage of its thin, inflammatorily changed membranous wall by an electrocauter during an oesophageal dissection. Even large para-carinal lesions can be treated with minimal invasion by using VATS-R, which was affirmed by the successful management of a patient (P2) with injury to the tracheal bifurcation and the right main bronchus. In addition, VATS repair allows the principle of minimally invasive surgery to be maintained in treating patients with more than one post-operative complication, each requiring emergency surgical correction. This approach was presented in a patient (P3) who simultaneously underwent thoracoscopic and laparoscopic surgery.

Summing up, the VATS-R minimally invasive technique, although neither very quick nor easy to perform, provides excellent results and avoids the use of, or conversion to, conventional thoracotomy, despite the fact that prompt on-table identification and adequate (open) surgical treatment of ITR is necessary for a good outcome [14]. As the current improvement of thoracoscopic technique and thoracic surgeons' experience/skills leads to decreases in the operative time, in the near future VATS repairs will take their deserved place in the surgery of iatrogenic injuries located in the distal third of the trachea and/or main bronchi. We believe that mid-distal, full-thickness membranous tracheal tears may 
be treated by direct VATS suture reinforced with the apposition of the oesophagus or gastric tube to the posterior trachea without a significant risk of early or late complications.

\section{Conclusions}

The minimally invasive thoracoscopic approach may be the method of choice in the treatment of intraoperative and post-intubation injuries of the tracheobronchial tree by direct suturing and suture line reinforcement.

\section{Conflict of interest}

The authors declare no conflict of interest.

\section{References}

1. Prokakis C, Koletsis E, Dedeilias P, et al. Airway trauma: a review on epidemiology, mechanisms of injury, diagnosis and treatment. J Cardiothorac Surg 2014; 9: 117.

2. Łochowski MP, Kozak J. Video-assisted thoracic surgery complications. Videosurgery Miniinv 2014; 9: 495-500.

3. Khitaryan A, Miziev I, Veliev C, et al. Case report of successful management of intraoperative tracheal rupture during thoracoscopic esophageal resection in patient with esophageal cancer. Int J Surg Case Rep 2019; 57: 42-6.

4. Łochowski MP, Brzeziński D, Rębowski M, et al. Complications after treating esophageal strictures with prostheses and stents - 20 years' experience. Videosurgery Miniinv 2016; 11: 295-9.

5. Łochowski MP, Szlachcińska A, Kozak J. Left mainstem bronchial laceration with perforation to right pleural cavity as complication after dynamic stent insertion. Videosurgery Miniinv 2014 9: 286-8.

6. Schneider T, Volz K, Dienemann H, et al. Incidence and treatment modalities of tracheobronchial injuries in Germany. Interact Cardiovasc Thorac Surg 2009; 8: 571-6.

7. Conti M, Pougeoise M, Wurtz A, et al. Management of postintubation tracheobronchial ruptures. Chest 2006; 130: 412-8.

8. Hofmann HS, Rettig G, Radke J, et al. latrogenic ruptures of the tracheobronchial tree. Eur I Cardiothorac Surg 2002; 21: 649-52.

9. Paraschiv M. Iatrogenic tracheobronchial rupture. J Med Life 2014; 7: 343-8

10. Koletsis E, Prokakis C, Baltayiannis N, et al. Surgical decision making in tracheobronchial injuries on the basis of clinical evidences and the injury's anatomical setting: a retrospective analysis. Injury 2012; 43: 1437-41.

11. Zhao Z, Zhang T, Yin X, et al. Update on the diagnosis and treatment of tracheal and bronchial injury. J Thorac Dis 2017; 9: E506.

12. Gabor S, Renner H. Indications for surgery in tracheobronchial ruptures. Eur J Cardiothorac Surg 2001; 20: 399-404.

13. Gomez-Caro Andres A, Moradiellos Diez FJ, Ausin Herrero P, et al. Successful conservative management in iatrogenic tracheobronchial injury. Ann Thorac Surg 2005; 79: 1872-8.
14. George SV, Samarasam I, Mathew G, et al. Tracheal injury during oesophagectomy - incidence, treatment and outcome. Trop Gastroenterol 2011; 32: 309-13.

15. Perez D, Hernandez F, Cano JR, et al. Large percutaneous tracheostomy-induced injury repair by thoracoscopic approach. Ann Thorac Surg 2015; 100: 1911.

16. Angelillo-Mackinlay T. Transcervical repair of distal membranous tracheal laceration. Ann Thorac Surg 1995; 59: 531-2.

17. Mussi A, Ambrogi MC, Menconi G, et al. Surgical approaches to membranous tracheal wall lacerations. J Thorac Cardiovasc Surg 2000; 120: 115-8.

18. Welter $S$, Krbek T, Halder R, et al. A new technique for complete intraluminal repair of iatrogenic posterior tracheal lacerations. Interact Cardiovasc Thorac Surg 2011; 12: 6-9.

Received: 2.04 .2021 , accepted: 30.05 .2021 